\title{
Risks assessment of urban participatory governance implementation
}

\author{
Mohammad Abuhasirah ${ }^{1}$ \& Isam Shahrour ${ }^{2}$ \\ ${ }^{1}$ Laboratoire de Génie Civil et géo-Environnement, Université de Lille, 59000 Lille, France \\ ${ }^{2}$ Laboratoire de Génie Civil et géo-Environnement, Université de Lille, 59000 Lille, France
}

\begin{abstract}
Participatory governance designates a set of regulations and processes that reinforces the participation of citizens and civil society in public process. It has an obvious role in the reinforcement of social capital, capacity building and social capital. It constitutes also a major pillar of the Smart City. Today, the implementation of the participatory governance becomes a "must": the absence of this governance presents high social and economic risks. On the other side, the implementation of this governance is complex and involves social and economic risks. This paper discusses these risks in order to help citizens and authorities to include risk assessment in the implementation of the participatory governance to reduce risks related to its implementation.
\end{abstract}

\section{Introduction}

Participatory governance designates a set of regulations and processes that reinforces the participation of citizens and civil society in the public policy process [1]. It has been embraced by major international organizations such [2], USAID (US Agency for international Development) and the World Bank [3].Citizens Participation has obvious role in building social capital through the creation of citizens networks and relationships. It provides people with opportunities to strengthen these networks and to build new ones [4] [5]. It results also in the reinforcement of the capacity building, which designates the ability of the community to deal with public and private affairs in a more effective way. It helps citizens and local communities to build a "Social capital" for collective problem solving [6].

Participatory governance became popular in the past three decades [7]. Some factors helped this concept to evolve such as the Information Technology revolution, the economic crises and the uprisings of pressure groups of the civil society asking for gender equality, social inclusion, transparency, fighting corruption, political and economic reforms [8] 
The implementation of the participatory governance becomes a "must": The absence of this governance presents high social and economic risks [9] [10]. On the other side, the implementation of this governance is complex and involves high social and economic risks. This paper discusses these risks in order to help citizens and authorities to include risk assessment in participatory governance process in order to guarantee its successful implementation.

\section{Urban participatory governance}

Urban participatory governance concerns the implementation of regulations and local policies that reinforce the participation of both citizens and civil society in the preparation of local decision-making as well as their inclusion to guarantee an effective social participation in the success of urban projects. The implementation of the urban participatory governance includes 4 phases (Figure 1): Identification, Information, Involvement and Evaluation.

\section{Identification}

\section{Information}

\section{Involvement}

\section{Evaluation}

Figure 1 Participatory governance implementation

The identification phase concerns the identification of the city stakeholders (citizens, civil society, economic actors, and public authorities) as well as national and local regulations and policies and their current implementations.

The information phase is crucial for the successful implementation of the participatory governance. It aims at providing the city stakeholders with information concerning urban projects through their life cycle: planning, design, construction and operating. Information will reinforce citizens' capacity to play an effective role in projects improvement and decision-making according to the rule "enhanced information leads to a more effective role in decision-making". The information sources should combine official sources as well as sources related to citizens and civil society. The information diffusion should combine digital technology tools (social media, hub, platform, virtual spaces,...) as well as physical spaces for meetings and discussions. Great care should be paid to provide information to habitants with limited possibilities to access to digital technology or suffering from disabilities.

The involvement phase concerns the effective participation of citizens and civil society in the preparation of the decision-making as well as their participation in the project evaluation. This goal could be achieved through participatory instances and processes such as neighborhood councils, resident advisory committees, diversity councils, youth councils, health councils, social centers, project houses, participatory budgets, citizen juries and public debates. The success of this phase is subjected to transparency and consideration of citizens input in the decision-making.

The evaluation phase is generally neglected in the implementation of the participatory governance despite its crucial role to get citizens feed-back of citizens (users' experiences) about the impact of urban projects on the quality of their life including social, economic and environmental dimensions. This phase requires establishing indicators to be monitored, providing collected information to urban stakeholders and sharing information, comments 
and analysis. It includes also information about how the citizens feedback was considered in projects update or as input to other projects.

\section{Risk related to the absence of urban participatory governance}

The city constitutes a complex system with a multitude of stakeholders. Citizens have a crucial role in cities. First of all, they are the principal component of the City. They contribute to the city development through economic and social activities as well as through taxes: The City owes to citizens its existence and development. On the other hand, city offers to citizens services (administration, health, education, culture, social..), work opportunities and security. The involvement of citizens in the city governance is then natural. Moreover, it is a "must" for the city development. This involvement allows cities to beneficiate from users' experiences, information concerning services deficiencies and performances and collective intelligence for design of high-quality socio-technical solutions. Thanks to the digital technology and to the presence of citizens everywhere in the city, citizens are considered as the most effective urban "smart sensors", which will help in effective city monitoring.

A city with effective participatory governance is characterized by transparency as well the existence of strong cooperation between citizens and authorities. It provides an image of peaceful and attractive city, which constitutes a key factor in attracting visitors and businesses.

On the other side, the absence of the participatory governance results in citizens demotivation, social tension, opaque governance with risk of corruption, privation of the city from users' experience. It could also create social frustration, which could result in large social protestation and instability as observed during the Arab Spring movements [11] and yellow vests movement in France [12]. The social tension could result in high economic and social losses, public properties damages and city image deterioration.

\section{Risks related to the implementation of the participatory governance}

The previous section showed why cities around the world should implement the participatory governance. However, the effective implementation of this governance is subjected to a multitude of barriers and risks.

The major risk is related to the complexity of the City, which is due to the high number of stakeholders, the fragmentation of local competencies and the large social, cultural and economic diversity with sometimes divergent interests. In addition, the technical and social management of the city is complex and could require high skills. Some politicians and administrative staffs believe that citizens are not qualified to deal with "complex" issues. A short-term vision of "effective" local governance could lead them to neglect citizens participation. In some cases, individual or pressure group constitute an effective barrier to share political or administrative decision power.

The implementation of the participatory governance in advanced democratic countries with strong regulation in local democracy, could suffer from politicians or administrative strategies to keep the power-decision without accounting. In this case, they implement the instances required by the regulations. But, since these instances are mainly "consultative", they do not consider their input in decision-making. 
Since effective participation is based on high quality information, some authorities do not provide pertinent information to citizens, which result in the deterioration of the capacity of citizens to provide pertinent input. These citizens-discouraging practices result in citizens demotivation and absence from governance participatory instances, with a risk to leave these instances to "selected", "professional" or "pressure" groups.

The implementation of the participative governance is subjected to citizens high civic sense and responsibility as well as to the presence of rich social fabric through associations as well as social and cultural activity. A successful implementation of the participatory governance must be accompanied by high education and awareness effort to reinforce both civic responsibility and building capacity of citizens and the society.

The participative governance implementation requires specific human and financial resources for functioning the instances related to the participative governance, ensuring interaction with citizens, financing participative projects and the construction of digital and non-digital tools and dispositive. In the context of tied budgets, cities could face difficulties to mobilize these resources, which are crucial for the implementation of the participative governance.

In the digital era, some cities use extensively the digital technology (social media, platforms, hubs, newsletters, virtual spaces, on-line consultation,..) to reinforce citizens participation. This use is effective for habitants, who are familiar with the digital technology, but could present two risks. First of all, it reduces the participation of habitants with difficulties to access to the digital technology and consequently to reinforce the digital fracture. The second risk is related to the disappearance of physical meeting spaces, which are crucial for citizens' information ideas confrontation and exchange with politicians.

The absence of the evaluation phase constitutes an important risk for the participative governance. It has several consequences, mainly accountability deficit, citizens demotivation and privation of the city from the citizens feed-back (users experience), which is crucial for understanding the social, economic and environmental impact of projects and taking the right decision and measurement for their effective improvement.

\section{Risk assessment}

Considering the high risks related to the absence or the application of participative governance, cities and authorities should conduct a risk assessment in order to identify the sources of risks related to the participative governance as well as their political, social and economic impacts. Risk assessment should result in strategies to reduce risks related to the implementation of the participative governance.

The risk assessment should include analysis of the social, political and economic context in the city with particular focus on social difficulties and citizens expectations. It should also identify the city stakeholders as well as related associations and organizations, citizens awareness and presence of pressure groups. The assessment should analyze requirements related to national and local regulations as well as recommendations of regional and international instances and their experience in local democracy. 
The assessment should analyze the local experience in participative governance including instances functioning and their effective impact on the social peace and citizens involvement in the city. It should explore barriers and difficulties related to the implementation of the participative governance as well as their social and economic costs and related risks. Analysis should be based on indicators such as the effective participation of citizens in participative governance instances as well as their social diversity, the consideration by authorities of citizens' propositions, the consultation of digital platforms, the participation in meetings, discussions on social media,.....

Risk assessment should result in the identification of major issues related to the participative governance risks such as implementation barriers, citizens expectations, instances functioning, citizens involvement, social and economic impact, digital opportunities and threats. For each issue, risk assessment should provide (table 1) indicators related to the likelihood of the risk (causes and probability), its severity (social, political and economic impact), risk score (Likelihood score * severity score), curative actions and predictive actions. Results of risk assessment should be discussed with city stakeholders to establish intervention priorities, agenda, dedicated resources, implementation process and evaluation.

Table 1: Components of risk assessment Output

\begin{tabular}{|c|l|l|l|l|l|}
\hline Issue & $\begin{array}{c}\text { Likehood } \\
\text { indicators }\end{array}$ & $\begin{array}{c}\text { severity } \\
\text { indicators }\end{array}$ & Risk score & $\begin{array}{c}\text { curative } \\
\text { actions }\end{array}$ & $\begin{array}{c}\text { Predictive } \\
\text { actions }\end{array}$ \\
\hline & & & & & \\
\hline & & & & & \\
\hline
\end{tabular}

\section{Conclusion}

Participative governance constitutes today a "must" for cities in order to involve citizens and civil society in local affaires and beneficiate from their large cultural and social diversity as input for urban projects and from their "users experience" for the evaluation of local policy and projects. Urban participatory governance constitutes also a major pillar for the Smart City.

Cities are subjected to risk related to both the implementation and non-implementation of the participative governance. This paper discussed these risks and proposed a methodology to help citizens and authorities to include risk assessment in the implementation of the participatory governance to reduce risks related to this implementation. 


\section{References}

[1] K. P. Andersson and F. Laerhoven, "From local strongman to facilitator: Institutional incentives for participatory municipal governance in Latin America," Comparative Political Studies, p. 1085-1111, 2007.

[2] UN Habitat, "Global Campaign of Urban Governance," 1999. [Online]. Available: http://mirror.unhabitat.org/content.asp?typeid=19\&catid=25\&cid=2097. [Accessed 03042018 ].

[3] World Bank, "Governance and development (English)," DC : The World Bank. http://documents.worldbank.org/curated/en/604951468739447676/Governance-anddevelopment, 1992.

[4] United Nations, Participatory Governance and the Millennium Development Goals (MDGs), New York, 2006.

[5] United Nations, Participatory Governance and the Millennium Development Goals (MDGs), 2008.

[6] R. D. Putnam, Bowling Alone: The Collapse and Revival of American Community, New York: Simon and Schuster, 2000.

[7] B. Wampler and S. L. McNulty, Does Participatory Governance Matter, Woodrow Wilson International Center for Scholars, 2011.

[8] A. Žuvela, L. Sutlović, M. Petrić , D. Mišković and D. Vidović, Do it Together. Practices and Tendencies of Participatory Governance in Culture in the Republic of Croatia., D. Vidović, Ed., Kultura Nova Foundation, 2018.

[9] F. J. Veiga and A. Aisen, "How does political instability affect economic growth?," European Journal of Political Economy, vol. 29, pp. 151-167, 2013.

[10] D. Batson, N. Ahmad and J. Tsang, "Four Motives for Community Involvement," Journal of Social Issues, vol. 58, pp. 429-445, 2003.

[11] E. Akhmetova, "The Arab Spring, Good Governance and Citizens' Rights," islam and civilisational renewal, pp. 334-350, 2014.

[12] E. TRUJILLO, "Comment Facebook a contribué à l'éclosion des gilets jaunes," 2311 2018. [Online]. Available: https://www.bfmtv.com/tech/comment-facebook-acontribue-a-l-eclosion-des-gilets-jaunes-1572771.html. [Accessed 1901 2019].

[13] United Nations Economic and Social Council, Definition of basic concepts and terminologies in governance, New York, 2006. 